\title{
Comparison of Synchronous and Metachronous Primary Carcinomas of the Bladder and Prostate
}

\author{
Ho Seok Chung, Young Ho Seo, Seung II Jung, Eu Chang Hwang, \\ Taek Won Kang, Dong Deuk Kwon
}

Department of Urology, Chonnam National University Medical School, Gwangju, Korea

\begin{abstract}
Purpose: The incidence of multiple primary malignant neoplasms increases with age. An unforeseen finding is the high number of prostate and bladder cancers pairs. Of prostate and bladder cancers pair as first primary and second primary cancers and vice versa, we investigated the differences in clinicopathological features between synchronous and metachronous primary carcinomas of the bladder and prostate.

Materials and Methods: Fifty-three patients diagnosed with dual prostate and bladder cancer in a 12-year period (2004-2015) excluding cases with incidental prostate cancer after radical cystectomy were reviewed. Enrolled patients were divided into 3 groups according to cancer development (group I, synchronous cancer; group II, prostate cancer with metachronous bladder cancer; group III, bladder cancer with metachronous prostate cancer). Each group was compared according to clinicopathological features.

Results: Median age was 72 years (range, 54-83 years). Groups I, II, and III comprised 29 (54.7\%), 8 (15.1\%), and 16 patients $(30.2 \%)$, respectively. Age, prostate-specific antigen, tumor stage, grade, multifocality of bladder tumor, and treatment modality did not show statistical differences between groups. However, group III showed a lower prostate cancer stage (National Comprehensive Cancer Network anatomic stage; $p=0.009$ ) and had low-risk of prostate cancers $(\mathrm{p}=0.025)$.

Conclusions: Bladder tumor showed no differences in the clinicopathological features between synchronous and metachronous primary carcinomas. However, metachronous prostate cancer showed better clinicopathological features of prostate cancer. It is important for clinicians to counselling and decision making in clinical situations.

(Korean J Urol Oncol 2017;15:44-50)
\end{abstract}

Key Words: Bladder $\cdot$ Carcinoma $\cdot$ Metachronous $\cdot$ Prostate $\cdot$ Synchronous

\section{INTRODUCTION}

The proposed criteria of multiple primary malignant neoplasms (MPMs) are histologically confirmed histologically malignancy of both tumors, anatomical distinctiveness of the tu-

Received October 27, 2016, Revised December 8, 2016,

Accepted December 26, 2016

Corresponding Author: Seung Il Jung

Department of Urology, Chonnam National University Hwasun Hospital, Chonnam National University Medical School, 322 Seoyang-ro, Hwasun 58128, Korea

E-mail: drjsi @ yahoo.co.kr

Tel: +82-61-379-8160, Fax: +82-61-379-7750 mors, and the second tumor not being a recurrence or metastasis of the first cancer. ${ }^{1}$ Further classification based on the timing of an each malignancy has been dichotomized as MPMs being synchronous or metachronous malignancies. ${ }^{2}$ The phenomenon of MPMs is increasingly being discussed in the literature due to the increased survival time of cancer patients after treatment and because of advances in diagnostic methods. Multiple neoplasms have been estimated to affect about $10 \%$ of all cancer patients. ${ }^{3-5}$

MPMs often occur in the bladder and prostate. Two primary carcinomas can coexist at the time of diagnosis, or develop consequently, sometimes years after resection of the first primary.

(i) (5) This is an Open Access article distributed under the terms of the Creative Commons Attribution Non-Commercial License (http://creativecommons.org/licenses/by-nc/4.0/) which permits unrestricted non-commercial use, distribution, and reproduction in any medium, provided the original work is properly cited. 2017 (C) Copyright The Korean Urological Oncology Society and The Korean Prostate Society. All Rights Reserved. 
Bladder cancer is the second most prevalent urologic cancer after prostate cancer. ${ }^{6}$ It may occur alone or associated with other cancers of the urogenital tract, particularly the prostate. Several authors report a surprisingly close association between bladder and prostate cancer. ${ }^{7-9}$ However most study focused on prostate cancer which was be incidentally found after radical cystoprostatectomy (RCP).

The purpose of the present study was to determine the differences in clinicopathological features between synchronous and metachronous primary carcinomas of the bladder and prostate.

\section{MATERIALS AND METHODS}

\section{Subjects}

This study protocol was reviewed and approved by the Institutional Review Board of Chonnam National University Hwasun Hospital (approval number: CNUHH-2015-077). Informed consent was waived by the board. We retrospectively reviewed patients with metachrous or synchronous cancer in bladder and prostate. We exclude patients with, prostate cancer which was incidentally found during the pathological test after a RCP for bladder cancer.

Fifty-three patients diagnosed with dual cancer (prostate cancer and bladder cancer) in a 12-year period (2004-2015) were retrospectively reviewed. Enrolled patients divided into 3 groups according to cancer development (group I, synchronous primary carcinomas of the bladder and prostate; group II, prostate cancer with metachronous bladder cancer; group III, bladder cancer with metachronous prostate cancer). Each group was compared concerning clinicopathological features. Collected data were age at initial cancer diagnosis, follow-up periods from initial cancer diagnosis, smoking, body mass index (BMI), and cause of death. Clinicopathological features of prostate cancer included prostate-specific antigen (PSA), Gleason score, National Comprehensive Cancer Network (NCCN) risk group, NCCN anatomic stage of prostate cancer, and treatment methods. Clinicopathological features of bladder cancer included histology (nonmuscle invasive bladder cancer [NMIBC], or muscle invasive bladder cancer [MIBC]), bladder tumor grade, multiplicity, and treatment methods.

\section{Tumor Classification}

We defined synchronous and metachronous cancer based on Moertel's definition. ${ }^{10}$ Synchronous cancers were defined as those occurring within 6 months of the first primary cancer, while metachrous cancers were defined as those occurring more than 6 months later.

\section{Statistical Analyses}

Statistical analyses were computed on IBM SPSS Statistics ver. 20.0 (IBM Co., Armonk, NY, USA) for Windows. For statistical analysis, we used the chi-square test for categorical variables, and 1-way analysis of variance test for continuous variables. The difference between groups was considered statistically significant if $\mathrm{p}$-values were $<0.05$.

\section{RESULTS}

Table 1 shows baseline characteristics of patients in this study. Median age was 72 years (range, 54-83 years). Median PSA level and BMI of patients was $2.35 \mathrm{ng} / \mathrm{mL}$ (range, 0.5-6.9 $\mathrm{ng} / \mathrm{mL}$ ) and $24.5 \mathrm{~kg} / \mathrm{m}^{2}$ (range, $19.0-30.5 \mathrm{~kg} / \mathrm{m}^{2}$ ), respectively. Thirty-three patients $(62.3 \%)$ of prostate cancer had been treated by active surveillance or androgen deprivation therapy with/without radiotherapy, and not by surgical interventional therapy. Patients with nonmuscle invasive urothelial carcinoma and muscle invasive urothelial carcinoma comprised 42 (79.2\%) and $11(20.8 \%)$, respectively. All patients had been initially treated by transurethral resection for bladder cancer, but most patients (41 patients, 77.4\%) had not been treated by adjuvant therapy (radiotherapy, chemotherapy, radical cystectomy). Two patients in group III were diagnosed prostate cancer by transrectal ultrasound-guided prostate biopsy in follow-up period and were performed RCP. The number and proportion of patients in groups I, II, and III was 29 (54.7\%), 8 (15.1\%), and $16(30.2 \%)$, respectively. Table 2 presents data on the comparison of clinicopathologic features stratified by cancer development. Median follow-up period was 32.0, 34.0, and 78.5 months in group I, II, and III, respectively, which showed a significant difference $(\mathrm{p}=0.007)$.

Mean PSA was $2.7 \pm 1.1,3.5 \pm 2.2$, and $2.4 \pm 0.9 \mathrm{ng} / \mathrm{dL}$ in groups I, II, and III, which showed no significant difference $(p=0.200)$. The number of patients who were current smokers or ex-smokers was 11,0 , and 7 in groups I, II, III ( $\mathrm{p}=0.197)$. There were no statistical differences of bladder cancer stage, grade, and multifocality between groups. However, group III showed a lower prostate cancer stage (NCCN anatomic stage; $\mathrm{p}=0.009)$ and had a lower risk of prostate cancer $(\mathrm{p}=0.025)$. 
Table 1. Baseline characteristics $(n=53)$

\begin{tabular}{|c|c|}
\hline Characteristic & Value \\
\hline Age (yr) & $72(54-83)$ \\
\hline Prostate-specific antigen* $(\mathrm{ng} / \mathrm{dL})$ & $2.35(0.5-6.9)$ \\
\hline Body mass index $\left(\mathrm{kg} / \mathrm{m}^{2}\right)$ & $24.5(19.0-30.5)$ \\
\hline Smoking & $18(34.0)$ \\
\hline \multicolumn{2}{|l|}{ Gleason score } \\
\hline 6 & $19(35.8)$ \\
\hline 7 & $17(32.1)$ \\
\hline 8 & $7(13.2)$ \\
\hline 9 & $6(11.3)$ \\
\hline 10 & $4(7.5)$ \\
\hline \multicolumn{2}{|l|}{ NCCN risk group } \\
\hline Low & $12(22.6)$ \\
\hline Intermediate & $15(28.3)$ \\
\hline High & $14(26.4)$ \\
\hline Very high & $7(13.2)$ \\
\hline Metastatic & $5(9.4)$ \\
\hline \multicolumn{2}{|l|}{ NCCN anatomic stage } \\
\hline I & $9(17.0)$ \\
\hline IIA & $14(26.4)$ \\
\hline IIB & $17(32.1)$ \\
\hline III & $6(11.3)$ \\
\hline IV & $7(13.2)$ \\
\hline \multicolumn{2}{|l|}{ Prostate cancer treatment } \\
\hline Active surveillance & $7(13.2)$ \\
\hline Androgen deprivation & $25(47.2)$ \\
\hline Radical prostatectomy & $16(30.2)$ \\
\hline Cystoprostatectomy & $4(7.5)$ \\
\hline $\mathrm{RT}$ with or without $\mathrm{ADT}$ & $1(1.9)$ \\
\hline \multicolumn{2}{|l|}{ Bladder tumor type } \\
\hline NMIBC & $42(79.2)$ \\
\hline MIBC & $11(20.8)$ \\
\hline \multicolumn{2}{|l|}{ Bladder tumor grade } \\
\hline G1 & $4(7.5)$ \\
\hline G2 & $22(41.5)$ \\
\hline G3 & $27(50.9)$ \\
\hline \multicolumn{2}{|l|}{ Bladder tumor multiplicity } \\
\hline$<3$ & $24(45.3)$ \\
\hline$\geq 4$ & $29(54.7)$ \\
\hline \multicolumn{2}{|l|}{ Bladder tumor treatment } \\
\hline TUR only & $41(77.4)$ \\
\hline TUR \& RC & $2(3.8)$ \\
\hline TUR \& RT & $1(1.9)$ \\
\hline TUR \& Chemo & $6(11.3)$ \\
\hline TUR \& RT \& Chemo & $1(1.9)$ \\
\hline TUR \& RC \& RT \& Chemo & $1(1.9)$ \\
\hline TUR \& RC \& Chemo & $1(1.9)$ \\
\hline \multicolumn{2}{|l|}{ Cancer development } \\
\hline Synchronous PCa \& BCa & $29(54.7)$ \\
\hline $\mathrm{PCa}$ with metachronous $\mathrm{BCa}$ & $8(15.1)$ \\
\hline $\mathrm{BCa}$ with metachronous $\mathrm{PCa}$ & $16(30.2)$ \\
\hline
\end{tabular}

Table 1. Continued

\begin{tabular}{lc}
\hline \multicolumn{1}{c}{ Characteristic } & Value \\
\hline Cause of death & \\
$\mathrm{PCa}$ & $5(9.4)$ \\
$\mathrm{BCa}$ & $6(11.3)$ \\
Not evaluable & $10(18.9)$ \\
Alive & $32(60.4)$ \\
\hline
\end{tabular}

Values are presented as median (range) or number of patients (\%). NCCN: National Comprehensive Cancer Network, RT: radiation therapy, ADT: androgen deprivation therapy, NMIBC: nonmuscle invasive bladder cancer, MIBC: muscle invasive bladder cancer, TUR: transurethral resection, RC: radical cystectomy, Chemo: chemotherapy, PCa: prostate cancer, BCa: bladder cancer.

*Logarithmically adjusted.

Treatment modality in each cancer showed no statistical difference between groups.

\section{DISCUSSION}

In this study, synchronous malignancies accounted for nearly $55 \%$ of the second primary malignancies and then bladder cancer with metachronous prostate cancer is the second most common. In an analysis of the Minneapolis Veterans Affairs tumor registry, prostate cancer was one of the most common cancers seen in a sample of synchronous and metachronous malignancies. ${ }^{7}$ During the period of this prior study, prostate cancer comprised almost $34 \%$ of all primary cancer diagnoses and $16 \%$ of all secondary cancer diagnoses. There were also high rates of primary ( $13.4 \%$ of cases) and secondary malignancies $(9.3 \%)$ in bladder and ureter cancers. An unforeseen finding was the high number of prostate and bladder cancers pairs. Of prostate and bladder cancers pair as first primary and second primary cancers and vice versa, they made up $12 \%$ of the multiple primary malignant tumor cohorts. ${ }^{7}$

Montie et al. ${ }^{8}$ and Abba et al. ${ }^{9}$ described high rates of incidental prostate cancers found as a result of cystoprostatectomy. Incidental prostate cancers found after cystoprostatectomy are usually insignificant prostate cancer and have no clinical significance. So in this study, we exclude the incidentally detected prostate cancers. However, in this study, synchronous malignancies accounted for nearly $55 \%$ of the second primary malignancies and then bladder cancer with metachronous prostate cancer is second most common. Prostate cancer with metachronous bladder cancer was the least because asymptomatic bladder 
Table 2. Comparison of clinicopathologic features stratified by cancer development

\begin{tabular}{|c|c|c|c|c|}
\hline Variable & Group I (n=29) & Group II $(n=8)$ & Group III $(n=16)$ & p-value \\
\hline Age $(\mathrm{yr})$, mean $\pm \mathrm{SD}$ & $72.0 \pm 6.1$ & $72.8 \pm 6.1$ & $70.3 \pm 7.7$ & $0.610^{*}$ \\
\hline Period between cancer diagnosis (mo), median \pm SD & $1.71 \pm 1.84^{*}$ & $51.63 \pm 43.22$ & $31.50 \pm 35.23$ & $0.001^{*}$ \\
\hline Follow-up (mo), median \pm SD & $32.0 \pm 39.7^{*}$ & $34.0 \pm 37.2$ & $78.5 \pm 51.4$ & 0.007 \\
\hline Prostate-specific antigen $(\mathrm{ng} / \mathrm{dL})$, mean $\pm \mathrm{SD}$ & $2.7 \pm 1.1$ & $3.5 \pm 2.2$ & $2.4 \pm 0.9$ & $0.200^{*}$ \\
\hline Body mass index $\left(\mathrm{kg} / \mathrm{m}^{2}\right)$, mean $\pm \mathrm{SD}$ & $24.2 \pm 2.5$ & $23.5 \pm 2.2$ & $24.6 \pm 2.5$ & $0.618^{*}$ \\
\hline Smoking & $11(37.9)$ & $0(0)$ & $7(43.7)$ & $0.197^{\dagger}$ \\
\hline Gleason score & & & & $0.367^{\dagger}$ \\
\hline 6 & $7(24.1)$ & $3(37.5)$ & $9(56.2)$ & \\
\hline 7 & $11(37.9)$ & $1(12.5)$ & $5(31.2)$ & \\
\hline 8 & $4(13.8)$ & $2(25.0)$ & $1(6.2)$ & \\
\hline 9 & $5(17.2)$ & $1(12.5)$ & $0(0)$ & \\
\hline 10 & $2(6.9)$ & $1(12.5)$ & $1(6.2)$ & \\
\hline NCCN risk group & & & & $0.025^{\dagger}$ \\
\hline Low & $4(13.8)$ & $2(25.0)$ & $6(37.5)$ & \\
\hline Intermediate & $9(31.0)$ & $1(12.5)$ & $5(31.2)$ & \\
\hline High & $10(34.5)$ & $0(0)$ & $4(25.0)$ & \\
\hline Very high & $5(17.2)$ & $2(25.0)$ & $0(0)$ & \\
\hline Metastatic & $1(3.4)$ & $3(37.5)$ & $1(6.2)$ & \\
\hline NCCN anatomic stage & & & & $0.009^{\dagger}$ \\
\hline I & $2(6.9)$ & $1(12.5)$ & $6(37.5)$ & \\
\hline IIA & $9(31.0)$ & $1(12.5)$ & $4(25.0)$ & \\
\hline IIB & $11(37.9)$ & $1(12.5)$ & $5(31.2)$ & \\
\hline III & $5(17.2)$ & $1(12.5)$ & $0(0)$ & \\
\hline IV & $2(6.9)$ & $4(50.0)$ & $1(6.2)$ & \\
\hline Prostate cancer treatment & & & & $0.646^{\dagger}$ \\
\hline Active surveillance & $4(13.8)$ & $0(0)$ & $3(18.8)$ & \\
\hline Androgen deprivation & $14(48.3)$ & $6(75.0)$ & $5(31.2)$ & \\
\hline Radical prostatectomy & $8(27.6)$ & $2(25.0)$ & $6(37.5)$ & \\
\hline Cystoprostatectomy & $2(6.9)$ & $0(0)$ & $2(12.5)$ & \\
\hline RT with or without ADT & $1(3.4)$ & $0(0)$ & $0(0)$ & \\
\hline Bladder tumor type & & & & $0.087^{\dagger}$ \\
\hline NMIBC & $23(79.3)$ & $7(87.5)$ & $12(75.0)$ & \\
\hline MIBC & $6(20.7)$ & $1(12.5)$ & $4(25.0)$ & \\
\hline Bladder tumor grade & & & & $0.092^{\dagger}$ \\
\hline G1 & $1(3.4)$ & $1(12.5)$ & $2(12.5)$ & \\
\hline $\mathrm{G} 2$ & $15(51.7)$ & $0(0)$ & $7(43.7)$ & \\
\hline G3 & $13(44.8)$ & $7(87.5)$ & $7(43.7)$ & \\
\hline Bladder tumor multiplicity & & & & $0.092^{\dagger}$ \\
\hline$<3$ & $15(51.7)$ & $1(12.5)$ & $8(50)$ & \\
\hline$\geq 3$ & $14(48.3)$ & $7(87.5)$ & $8(50)$ & \\
\hline Bladder tumor treatment & & & & $0.851^{\dagger}$ \\
\hline TUR only & $22(75.9)$ & $7(87.5)$ & $12(75.0)$ & \\
\hline TUR \& RC & $1(3.4)$ & $0(0)$ & $1(6.2)$ & \\
\hline TUR \& RT & $1(3.4)$ & $0(0)$ & $0(0)$ & \\
\hline TUR \& Chemo & $3(10.3)$ & $1(12.5)$ & $2(12.5)$ & \\
\hline TUR \& RT \& Chemo & $1(3.4)$ & $0(0)$ & $0(0)$ & \\
\hline TUR \& RC \& RT \& Chemo & $1(3.4)$ & $0(0)$ & $0(0)$ & \\
\hline TUR \& RC \& Chemo & $0(0)$ & $0(0)$ & $1(6.2)$ & \\
\hline
\end{tabular}


Table 2. Continued

\begin{tabular}{|c|c|c|c|c|}
\hline Variable & Group I $(n=29)$ & Group II $(n=8)$ & Group III (n=16) & p-value \\
\hline Cause of death & & & & $0.855^{\dagger}$ \\
\hline $\mathrm{PCa}$ & $3(10.3)$ & $1(12.5)$ & $1(6.2)$ & \\
\hline $\mathrm{BCa}$ & $3(10.3)$ & $1(12.5)$ & $2(12.5)$ & \\
\hline Not evaluable & $4(13.8)$ & $1(12.5)$ & $5(31.2)$ & \\
\hline Alive & 19 (65.5) & $5(62.5)$ & $8(50.0)$ & \\
\hline
\end{tabular}

Values are presented as number of patients (\%) unless otherwise indicated.

Group I: synchronous bladder and prostate cancer (occurring within 6 months), group II: prostate cancer with metachronous bladder cancer (occurring more than 6 months), group III: bladder cancer with metachronous prostate cancer (occurring more than 6 months).

SD: standard deviation, NCCN: National Comprehensive Cancer Network, RT: radiation therapy, ADT: androgen deprivation therapy, NMIBC: nonmuscle invasive bladder cancer, MIBC: muscle invasive bladder cancer, TUR: transurethral resection, RC: radical cystectomy, Chemo: chemotherapy, PCa: prostate cancer, BCa: bladder cancer.

${ }^{*}$ One-way analysis of variance. ${ }^{\dagger}$ Chi-square.

cancers could be unintentionally found as part of or due to symptoms from transurethral resection of prostate cancer ${ }^{11}$ or evaluation of hematuria.

Due to the high number of these synchronous malignancies occurring in our cohort, there was also the possibility that shared molecular pathways of carcinogenesis may exist in these 2 histologically unique cancers. Further investigation into this hypothesis is warranted. Old age is a common risk factor for bladder and prostate cancer, because prostate and bladder cancers occur more often in elderly patients as the incidence of malignancies increases with age. ${ }^{12}$ In addition, the combination of prostate and bladder cancer might be due to their common embryological origin with similarities at the molecular level. ${ }^{9,11}$ Indeed, the involvement of 3 oncogenes and deletion of 3 gene suppressors ( $\mathrm{Rb}, \mathrm{p} 53$, and $23 \mathrm{~nm}$ ) have been described as possible causes for this association. ${ }^{13}$ Also, the prostate stem cell antigen is overexpressed in the most transitional cell carcinomas and more genotypes of rapid $\mathrm{N}$-acetyltransferase was observed in patients with these 2 cancers. This enzyme, known for its activation of carcinogenic amines, is higher in patients with double cancers than in control groups. ${ }^{13,14}$ Prostate and bladder cancers may be secondary to urinary stasis. ${ }^{15}$ The incidence of bladder cancer in the diverticulum is estimated at $10 \% .{ }^{16}$ Kirby et al. ${ }^{15}$ observed a reflux of urine with prostatic intraurinary stasis in the peripheral zone of the prostate. The authors concluded that carcinogens identified in the bladder may have an effect on the development of prostate cancer. Chronic inflammation and a common carcinogen in the bladder and prostate may be responsible for the concurrent cancers. ${ }^{15-18}$

It remains true that the incidence of prostate cancer in a ser- ies of radical cystoprostatectomies with unscreened and unselected patients could be nearly $50 \% .{ }^{19,20}$ In this study, we exclude patients with the incidentally detected prostate cancer. However, synchronous prostate cancer or bladder cancer detected within 6 months accounted for nearly $55 \%$ of the second primary malignancies and then bladder cancer with metachronous prostate cancer is second most common.

There were more group III patients (metachronous prostate cancer) than group II patients (metachronous bladder cancer). This may be due to the fact that prostate cancer screening is routinely done in elderly patients. Indeed, the incidence of prostate cancer in patients with bladder cancer is 18 times higher than in the general population. However, the incidence of bladder cancer in patients with prostate cancer is also 19 times higher than in the general population. This risk varies from $2.8 \%$ to $70 \% .^{8,11,21,22}$ These phenomena may be due to incidental findings resulting in a second malignancy diagnosis. For example, most patients with prostate cancers will be checked by imaging studies to determine cancer stage and their surgical candidacy. This imaging study may result in unintentional screening test that diagnoses a second primary cancer.

Significant differences in the stage of prostate cancer at diagnosis of the first and second malignancies were seen in the synchronous and metachronous cohorts. Patients who had metachronous prostate cancer (group III) tended to present with earlier stage disease and low-risk prostate cancer than those with synchronous malignancies. However, stage IV primary prostate cancer disease at presentation was more common in the metachronous bladder cancer group (50\%) than in the synchronous cancer group (6.9\%). Differences in survival are likely to con- 
tribute to these findings. For someone presenting with advanced disease, survival would be poorer than those presenting with early stage disease. Androulakakis et al. ${ }^{23}$ suggested that the coexistence of prostate cancer and bladder cancer did not affect the prognosis of either disease. Patient prognosis appears to be related to the characteristics of each tumor on an individual basis. No worse survival in patients with both cancers compared with those with bladder cancer alone has been described. ${ }^{24}$ Prognosis is related to the extension of each cancer. However, Konski et al. ${ }^{25}$ found that the stage and grade of bladder cancer are, in terms of prognosis, greater than those of prostate cancer. Moutzouris et al. ${ }^{26}$ followed 16 patients with prostate cancer. They found prostate cancer recurrence in 1 patient with apical prostate cancer who recurred at the anastomosis between the neobladder and the urethra. After a mean follow-up of 39 months, 7 patients died of metastatic bladder cancer, while the patient with prostate cancer recurrence was still alive.

However, even if prostate cancer is not strongly associated with oncologic outcome in patients with dual cancer, some authors have emphasized the importance of diagnosis of prostate cancer in patients with MIBC for a correct approach to surgical alternatives. Which is by an apex sparing approach and/or the prostate capsule-preserving in order to preserve sexuality and urinary continence in young adult patients. ${ }^{27-29}$ In this study, patients who had metachronous prostate cancer tended to present with earlier stage disease and low-risk prostate cancer. Metachronous prostate cancer after prostate-sparing radical cystectomy can be diagnosed during follow-up as well, but this is unlikely to be the main cause of mortality. Prostate cancer identified during follow-up after prostate-sparing radical cystectomy can be approached the same way as under 'noncystectomy' circumstances.

One limitation of our study is the retrospective design that leads to selection bias, firstly. Secondly, our study consisted of only 53 patients, and so cannot represent general population. In addition, group 2 had only 8 patients, which limits accuracy. Lastly, despite lower NCCN risk and lower NCCN stage of prostate cancer in group III, there was no significant difference in cause of death between 3 groups. This result might be due to a longer follow-up period in group III than other groups. So, investigation by long-term follow-up in groups I and II and multiple center study could be helpful to understand the properties of synchronous and metachronous bladder and prostate carcinomas.

\section{CONCLUSIONS}

We found that synchronous primary malignancies of prostate and bladder are more common than metachronous bladder or prostate malignancies. Bladder tumor showed no differences in the characteristics and clinicopathological features between synchronous and metachronous primary carcinomas. However, metachronous prostate cancer showed better clinicopathological features of prostate cancer. It is important for clinicians to counselling and decision making in considering of prostate-sparing radical cystectomy.

\section{CONFLICT OF INTEREST}

No potential conflict of interest relevant to this article was reported.

\section{REFERENCES}

1. Warren S, Gates O. Multiple primary malignant tumors: a survey of the literature and statistical study. Am J Cancer 1932; $16: 1358-414$

2. Moertel CG, Bargen JA, Dockerty MB. Multiple carcinomas of the large intestine: a review of the literature and a study of 261 cases. Gastroenterology 1958;34:85-98

3. Luciani A, Ascione G, Marussi D, Oldani S, Caldiera S, Bozzoni S, et al. Clinical analysis of multiple primary malignancies in the elderly. Med Oncol 2009;26:27-31

4. Frödin JE, Ericsson J, Barlow L. Multiple primary malignant tumors in a national cancer registry: reliability of reporting. Acta Oncol 1997;36:465-9

5. Lawniczak M, Gawin A, Jaroszewicz-Heigelmann $\mathrm{H}$, Rogoza-Mateja W, Raszeja-Wyszomirska J, Białek A, et al. Synchronous and metachronous neoplasms in gastric cancer patients: a 23-year study. World J Gastroenterol 2014;20:7480-7

6. Devesa SS, Silverman DT, Young JL Jr, Pollack ES, Brown $\mathrm{CC}$, Horm JW, et al. Cancer incidence and mortality trends among whites in the United States, 1947-84. J Natl Cancer Inst 1987;79:701-70

7. Powell S, Tarchand G, Rector T, Klein M. Synchronous and metachronous malignancies: analysis of the Minneapolis Veterans Affairs (VA) tumor registry. Cancer Causes Control 2013;24:1565-73

8. Montie JE, Wood DP Jr, Pontes JE, Boyett JM, Levin HS. Adenocarcinoma of the prostate in cystoprostatectomy specimens removed for bladder cancer. Cancer 1989;63:381-5 
9. Abbas F, Hochberg D, Civantos F, Soloway M. Incidental prostatic adenocarcinoma in patients undergoing radical cystoprostatectomy for bladder cancer. Eur Urol 1996;30:322-6

10. Moertel CG. Multiple primary malignant neoplasms: historical perspectives. Cancer 1977;40(4 Suppl):1786-92

11. Chun TY. Coincidence of bladder and prostate cancer. J Urol 1997; $157: 65-7$

12. Koutsopoulos AV, Dambaki KI, Datseris G, Giannikaki E, Froudarakis M, Stathopoulos E. A novel combination of multiple primary carcinomas: urinary bladder transitional cell carcinoma, prostate adenocarcinoma and small cell lung carcinoma: report of a case and review of the literature. World J Surg Oncol 2005;3:51

13. Fradet Y. Molecular and immunologic approaches in the management of bladder cancer. Urol Clin North Am 1991;18: 515-24

14. Singh A, Jones RF, Friedman H, Hathir S, Soos G, Zabo A, et al. Expression of p53 and pRb in bladder and prostate cancers of patients having both cancers. Anticancer Res 1999; 19(6B):5415-7

15. Kirby RS, Lowe D, Bultitude MI, Shuttleworth KE. Intra-prostatic urinary reflux: an aetiological factor in abacterial prostatitis. Br J Urol 1982;54:729-31

16. Das $\mathrm{S}, \mathrm{Amar} \mathrm{AD}$. Vesical diverticulum associated with bladder carcinoma: therapeutic implications. J Urol 1986;136:1013-4

17. Platz EA, De Marzo AM. Epidemiology of inflammation and prostate cancer. J Urol 2004;171(2 Pt 2):S36-40

18. Singh A, Kinoshita Y, Rovito PM Jr, Landas S, Silberstein J, Nsouli I, et al. Higher than expected association of clinical prostate and bladder cancers. J Urol 2005;173:1526-9

19. Ruffion A, Manel A, Massoud W, Decaussin M, Berger N, Paparel $\mathrm{P}$, et al. Preservation of prostate during radical cystectomy: evaluation of prevalence of prostate cancer associated with bladder cancer. Urology 2005;65:703-7

20. Pettus JA, Al-Ahmadie H, Barocas DA, Koppie TM, Herr H, Donat SM, et al. Risk assessment of prostatic pathology in patients undergoing radical cystoprostatectomy. Eur Urol 2008;53:370-5
21. Troncoso P, Babaian RJ, Ro JY, Grignon DJ, von Eschenbach AC, Ayala AG. Prostatic intraepithelial neoplasia and invasive prostatic adenocarcinoma in cystoprostatectomy specimens. Urology 1989;34(6 Suppl):52-6

22. Winfield HN, Reddy PK, Lange PH. Coexisting adenocarcinoma of prostate in patients undergoing cystoprostatectomy for bladder cancer. Urology 1987;30:100-1

23. Androulakakis PA, Schneider HM, Jacobi GH, Hohenfellner R. Coincident vesical transitional cell carcinoma and prostatic carcinoma. Clinical features and treatment. Br J Urol 1986; 58:153-6

24. Damiano R, Di Lorenzo G, Cantiello F, De Sio M, Perdonà $\mathrm{S}$, D'Armiento M, et al. Clinicopathologic features of prostate adenocarcinoma incidentally discovered at the time of radical cystectomy: an evidence-based analysis. Eur Urol 2007;52: 648-57

25. Konski A, Rubin P, DiSantangnese PA, Mayer E, Keys H, Cockett A, et al. Simultaneous presentation of adenocarcinoma of prostate and transitional cell carcinoma of bladder. Urology. 1991;37:202-6

26. Moutzouris G, Barbatis C, Plastiras D, Mertziotis N, Katsifotis C, Presvelos V, et al. Incidence and histological findings of unsuspected prostatic adenocarcinoma in radical cystoprostatectomy for transitional cell carcinoma of the bladder. Scand J Urol Nephrol 1999;33:27-30

27. Colombo R, Bertini R, Salonia A, Naspro R, Ghezzi M, Mazzoccoli B, et al. Overall clinical outcomes after nerve and seminal sparing radical cystectomy for the treatment of organ confined bladder cancer. J Urol 2004;171:1819-22

28. Vallancien G, Abou El Fettouh H, Cathelineau X, Baumert H, Fromont G, Guillonneau B. Cystectomy with prostate sparing for bladder cancer in 100 patients: 10-year experience. J Urol 2002;168:2413-7

29. Mertens LS, Meijer RP, de Vries RR, Nieuwenhuijzen JA, van der Poel HG, Bex A, et al. Prostate sparing cystectomy for bladder cancer: 20-year single center experience. J Urol 2014;191:1250-5 